\title{
Sexualidade e educação sexual na percepção docente ${ }^{1}$
}

\section{Sexuality and sex education in teachers' perception}

\author{
Glauberto da Silva Quirino ${ }^{2}$ \\ João Batista Teixeira da Rocha ${ }^{3}$
}

\begin{abstract}
RESUMO
Este artigo objetivou conhecer a percepção sobre sexualidade e educação sexual dos/as professores/as do Ensino Fundamental e Médio de uma escola pública de Juazeiro do Norte-CE, Brasil. Desenvolveu-se um estudo descritivo, de natureza qualitativa, de setembro de 2009 a fevereiro de 2010, com sete professores/as, por meio da observação e entrevista semiestruturada, com os seguintes questionamentos: o que é para você sexualidade? O que você entende por educação sexual? Os dados foram organizados em cinco categorias e analisados de forma interpretativa. $\mathrm{O}$ conceito de sexualidade foi dividido em duas categorias, sexo e opção sexual. Além de seus aspectos corporais, houve elementos espirituais e de expressão do amor entre os seres, embora estes fossem secundários aos atributos genitais e do intercurso sexual, circundados pelo caráter natural. A educação sexual foi pautada sobre três eixos: relação sexual, fisiologia corporal e comportamento social, constituindo tema relevante, a ser trabalhado a partir do quarto ou quinto ano do Ensino Fundamental, cujas aulas de ciências figuram como o espaço mais adequado para se tratar do assunto. $\mathrm{O}$ trabalho docente necessita de constante renovação, sendo preciso superar o modelo biomédico/científico na sexualidade, considerando suas
\end{abstract}

${ }^{1}$ Coordenação de Aperfeiçoamento de Pessoal de Nível Superior (CAPES).

${ }^{2}$ Doutorando em Educação em Ciências: Química da Vida e Saúde, da Universidade Federal de Santa Maria (UFSM-RS). Professor Assistente da Universidade Regional do Cariri. Membro do GRUPESC, linha de pesquisa: Sexualidade e reprodução e sua interface com a Enfermagem no cuidado individual e coletivo (URCA). Brasil. E-mail: glaubertoce@hotmail.com

${ }^{3}$ Orientador. Pós-Doutor pelo Departamento de Bioquímica Médica, da Universidade Federal do Rio de Janeiro (UFRJ). Professor do Programa de Pós-Graduação em Educação em Ciências: Química da Vida e Saúde (UFSM-RS). Bolsista de Produtividade em Pesquisa do CNPq - Nível 1A. Brasil. E-mail: jbtrocha@yahoo.com.br 
dimensões histórica, social e cultural, cuja transversalidade das ações deve ser uma meta a ser alcançada nos diversos campos do saber.

Palavras-chave: sexualidade; educação sexual; gênero; escola.

\begin{abstract}
This article aimed to know the perception of sexuality and sex education of teachers of the Elementary and Secondary Education of a public school in Juazeiro do Norte-CE, Brazil. We developed a descriptive study with qualitative approach carried out from September 2009 to February 2010 with seven teachers, through observation and semi-structured interview, with the following questions: What is sexuality for you? What do you understand by sex education? Data were organized into five categories and analyzed in an interpretive way. The concept of sexuality was divided into two categories: gender and sexual orientation. Besides the physical aspects, there were spiritual and expression elements of love among humans, although these were secondary to genital attributes and sexual intercourse, surrounded by nature character. Sex education was based on three themes: sexual intercourse, body physiology and social behavior, constituting an important issue to be worked from the fourth or fifth year of elementary school, where science classes are listed as the most appropriate space to address the issue. The teaching profession needs constant renewal, being necessary to overcome the biomedical/scientific model in sexuality, considering its historical, social and cultural dimensions, where cross-sectional actions should be a goal to be achieved in several fields of knowledge.
\end{abstract}

Keywords: sexuality; sex education; gender identity; school.

\title{
Introdução
}

O ano de 2010 reacendeu o debate sobre a educação sexual no espaço escolar através da distribuição, por parte do Governo Federal, de um artefato didático que se propunha a subsidiar professores/as no processo de orientação pedagógica acerca do tema sexualidade/sexo. Esse evento foi acompanhado de inúmeras críticas por parte de setores conservadores do Poder Legislativo e da sociedade civil, que culminou no recolhimento do material e na procrastinação da discussão sobre o assunto.

Dentro dessa perspectiva, Foucault (2009a, p. 42) afirma que é uma característica das sociedades modernas incentivarem o discurso sobre o sexo, entre- 
tanto, valorizando-o como "o segredo". Para tanto, dentro do espaço formal de educação brasileira, a orientação sexual ${ }^{4}$ está inserida como um tema transversal nos Parâmetros Curriculares Nacionais (PCN). Contudo, parece coerente destacar que as iniciativas didático-pedagógicas de inclusão da temática na pauta de discussão na escola ainda apresentam resistências para a eficaz implementação.

O espaço escolar caracteriza-se como plural tanto do ponto de vista de seus membros, estudantes, professores/as, dirigentes e funcionários/as, bem como do ideológico, pois neste pode ser encontrada uma diversidade de ideias e ações que podem legitimar ou subverter a ordem dominante. Entretanto, historicamente, a escola, por intermédio de seus/as componentes, tem reproduzido os interesses do Estado e da sociedade como um todo.

Um exemplo do controle do Estado sobre uma esfera da sexualidade pode ser observado pela experiência da Revolução Cubana, cujos jovens homossexuais eram expulsos da escola mediante humilhações e apedrejamento se os mesmos fossem flagrados em atos comprometedores. A partir de então, o jovem recebia uma carta que o impedia de matricular-se em qualquer outra escola do Estado. Ser homossexual em "Cuba representava uma das maiores desgraças que podem acontecer a um ser humano" (ARENAS, 2009, p. 72).

No Brasil, constatou-se a necessidade de discutir os aspectos da sexualidade no espaço escolar através dos temas transversais que se configuram como uma tentativa de voltar a prática educacional para a construção de uma realidade social, política e ambiental cidadã, sendo seus conteúdos e objetivos incorporados nas áreas de conhecimento existentes e no trabalho educativo escolar. Esse pressuposto baseia-se na ideia de que a escola não muda a sociedade, mas pode transcender o espaço de reprodução para o espaço de transformação, uma vez que as práticas pedagógicas são sociais e políticas (BRASIL, 2000).

Nesse sentido, as diversas áreas do conhecimento que são ministradas no espaço escolar precisam atentar-se para a questão da sexualidade e da educação sexual. No entanto, isso pressupõe que o corpo docente necessita estar preparado para implementar o processo educativo na construção dessa cidadania. Isto indica que os/as interlocutores/as da ação pedagógica, de modo especial, os/as professores/as precisam de embasamento teórico e didático coerentes com as demandas sociais dos/as estudantes.

Segundo Moizés e Bueno (2010), destacar o/a professor/a como agente central na consecução dos objetivos da transversalidade dos PCN faz refletir

\footnotetext{
${ }^{4} \mathrm{O}$ termo orientação sexual é utilizado nos Parâmetros Curriculares Nacionais para designar as possíveis intervenções educativas que a escola produz sobre a sexualidade e não ao direcionamento do afeto no exercício da sexualidade em relação a outro sujeito. Prefere-se nesse sentido utilizar o termo educação sexual do que orientação sexual.
} 
sobre sua real condição de trabalho e a qualidade de sua formação profissional, uma vez que sua capacitação para o desempenho eficaz e emancipador sobre a sexualidade na escola se constitui em um grande desafio.

Embora a sexualidade seja um assunto que tenha ganhado visibilidade a partir dos estudos de Freud, no início do século XX, e Michel Foucault, na década de 1980, sua abordagem ainda está voltada para características normativas marcadas, principalmente, por aspectos biológicos (COSTA; COELHO, 2011). A superação dos pressupostos biomédicos para um modelo que considere a sexualidade como o resultado de múltiplos fatores socioculturais, incluindo em seu escopo de análise a perspectiva das relações de gênero de forma transversal, ainda é incipiente.

A partir dessa perspectiva, a sexualidade não pode permanecer como assunto restrito das ciências biológicas, valorizando os aspectos físicos e os hábitos saudáveis, em um discurso essencialista. Não se pode tratá-la ao nível do senso comum, expondo concepções superficiais e pessoais como verdadeiras, acabadas, adotando seus valores como universais, enfim, abordando a sexualidade de maneira simplista, primária e, sobretudo, empírica (JARDIM; BRÊTAS, 2006). Outrossim, os/as professores/as e as famílias possuem admiráveis papéis na formação dos/as jovens cidadãos/ãs, em que a escola é um importante espaço para o desenvolvimento de um programa de educação para a saúde e para a vida entre crianças e adolescentes, pois, por meio da discussão da temática sexualidade e de seus desdobramentos, pode-se motivar reflexões individuais e coletivas que possam contribuir para a minimização de ações discriminatórias e preconceituosas.

Portanto, o objetivo desta pesquisa foi conhecer a percepção sobre sexualidade e educação sexual dos/as professores/as do Ensino Fundamental e Médio de uma escola pública de Juazeiro do Norte-CE. É a partir desse conhecimento que valores, conceitos e representações sobre a temática sexualidade e seu processo educativo podem ser acessados, apreendidos e utilizados como subsídio para propostas pedagógicas que favoreçam a autonomia e o aprendizado da cooperação e da participação social. Portanto, ao se tratar de temáticas sociais, além de atitudes e procedimentos, é fundamental o trabalho de natureza conceitual, para que se possa aprender a formular questões a respeito da realidade e de suas relações (BRASIL, 2000).

Para tanto, desenvolveu-se um estudo descritivo, de natureza qualitativa. De acordo com Gil (2009), a pesquisa descritiva tem como principal objetivo a descrição das características de uma determinada população ou de um determinado fenômeno. Para Minayo (2008), a abordagem qualitativa se aplica ao estudo das relações, das representações, das crenças, das percepções e das opiniões, fruto das interpretações que as pessoas fazem a respeito de como vivem, pensam 
e sentem. Investiga um nível de realidade que não pode ser quantificado, trabalhando com o universo dos significados, das motivações, aspirações, crenças, valores e atitudes. Nesse sentido, está mais adequada aos segmentos grupais delimitados e focalizados sob a perspectiva dos atores e atrizes. Caracteriza-se, ainda, pela empiria e pela sistematização do conhecimento até a compreensão da lógica interna do grupo ou do processo em estudo.

O trabalho de campo foi desenvolvido de setembro de 2009 a fevereiro de 2010, em que foram realizadas observações de aulas nas turmas de $9^{\circ}$ ano do Ensino Fundamental e $1^{\circ}$ ano do Ensino Médio, de reuniões de professores/as nos intervalos das aulas e de atividades complementares na sala de multimeios. Foram assistidas as aulas de Matemática, Física, Português, Artes, Química, Educação Física, Biologia, Filosofia, Sociologia e Geografia.

Além das observações, foram procedidas a sete entrevistas semiestruturadas com os/as professores/as que tiveram suas aulas observadas. Na ocasião, foi solicitado que respondessem aos seguintes questionamentos: o que é para você sexualidade? O que você entende por educação sexual? Foi utilizado um gravador de áudio e as entrevistas foram realizadas na escola, em sala reservada e de forma individual.

Após a realização das entrevistas, realizou-se escuta exaustiva do material. Em seguida, todas as entrevistas foram transcritas, as quais foram organizadas em um quadro de convergência e divergência, sendo utilizado o método colorimétrico, cujos depoimentos semelhantes recebiam marcação com cores iguais. Posteriormente à construção do quadro mencionado, identificou-se o núcleo central, depois as ideias foram agrupadas e os temas identificados. Transcorrida essa etapa, elaboraram-se as categorias e, a partir destas, foi realizada a análise de cada tema que compõe a descrição dos resultados obtidos (MINAYO, 2008). Com esses dados, foi possível formular o corpo de análise, desenvolvendo cinco categorias temáticas do estudo. Por fim, foi realizada a compreensão e a interpretação dos dados à luz da literatura. Os nomes dos/as sujeitos/as são fictícios e foram inspirados em materiais escolares: lápis, caneta, papel, pincel, borracha, caderno e livro.

\section{Cenário e atores/atrizes do estudo}

A pesquisa foi realizada em uma escola de Ensino Fundamental e Médio pertencente à rede estadual de ensino do município de Juazeiro do Norte-CE, que oferecia ensino para 1.485 estudantes nas séries: $9^{\circ}$ ano do Ensino Fundamental 
e Ensino Médio Regular, distribuídos em três períodos: manhã, tarde e noite. No período da manhã, funcionavam 11 salas, duas classes de Ensino Fundamental e nove classes de Ensino Médio ( $1^{\circ}$ ao $3^{\circ}$ ano); no período da tarde, nove salas, uma classe de Ensino Fundamental e oito classes do Ensino Médio. No período da noite, 11 salas, todas do Ensino Médio. O quadro docente da escola era composto de 17 professores/as efetivos/as e 21 professores/as temporários/as, além de 15 servidores/as que desempenhavam funções técnicas e administrativas.

O município de Juazeiro do Norte está localizado ao Sul do Estado do Ceará, à distância de $538 \mathrm{~km}$ da capital, Fortaleza, e conta com, aproximadamente, 249.829 habitantes (IBGE, 2009). A escola foi criada em 1976 e teve o Ensino Médio instalado em 1999. É mantida pela Secretaria de Educação do Governo do Estado do Ceará. O prédio era próprio, dotado de infraestrutura satisfatória e contava com as seguintes dependências: setor administrativo (diretoria, secretaria, almoxarifado e sanitários masculino e feminino), setor de serviços (cantina, cozinha, pátio coberto e sanitários masculino e feminino) e setor pedagógico (11 salas de aulas, uma sala de informática, uma sala de multimeios, uma sala de professores, uma sala de coordenação, uma quadra de esportes coberta e um laboratório de ciências físicas e exatas). Quanto aos recursos pedagógicos, a escola dispunha de dois retroprojetores, seis televisores, um videocassete, três DVD players, dois aparelhos de som, uma máquina de fotocópia e uma máquina fotográfica digital.

A clientela da unidade escolar era na sua maioria proveniente das camadas sociais mais populares, predominando alunos/as oriundos/as de famílias com baixo grau de instrução de pelo menos seis bairros do município. No seu entorno, existia um número importante de estabelecimentos comerciais de pequeno, médio e grande portes, oficinas mecânicas, lanchonetes e pequenas indústrias. Contava, ainda, com o maior centro de abastecimento da Região Metropolitana do Cariri.

As salas de aula mediam, aproximadamente, 48 metros quadrados e eram organizadas em cinco filas; havia na entrada um quadro-negro e um branco, as paredes eram revestidas de cerâmica até a metade e a outra metade pintada com um tom de amarelo, algumas cerâmicas se encontravam quebradas, piso industrial, cobertura do teto de policloreto de vinila (PVC), ventiladores de teto, oito lâmpadas fluorescentes, havia uma mesa de tampo de mármore e uma cadeira, destinadas para o/a professor/a, as cadeiras escolares eram de madeira e muitas estavam quebradas, duas janelas grandes subdivididas em seis portinholas que se abriam, algumas quebradas, pintadas de cinza, a porta da sala era de ferro, a sala era ampla, clara e arejada, as paredes, janelas, quadros e cadeiras riscadas com tinta de corretivo. Os/As alunos/as vestiam, em sua maioria, a blusa padrão da escola, calças jeans e tênis, a maior parte da turma era constituída de mulheres. 
Os/As sujeitos/as que participaram da pesquisa foram quatro professoras e três professores, com média de idade de 37,7 anos, variando de 30 a 45 anos. Todos/as se declararam católicos/as. Quanto ao estado civil, três estavam solteiros/as, três casados/as e um/a divorciado/a. Em relação à formação acadêmica, todos/as se graduaram em Instituições de Ensino Superior pública e apenas um/a docente não tem pós-graduação lato sensu.

Quanto aos aspectos do trabalho docente, seis professores/as tinham carga horária semanal de 40 horas/aula e apenas um/a de 20 horas/aula, quatro possuem contrato temporário e três faziam parte do quadro efetivo da escola. O tempo de atividade na escola variou de um a oito anos, sendo que quatro professores/ as trabalhavam em outra unidade escolar do município e os demais apenas na unidade pesquisada; entretanto, nenhum/a possuía atividade laboral em escola de caráter privado, sendo todos/as funcionários/as públicos/as. Em geral, ministravam mais de uma disciplina alinhada à área de formação acadêmica.

\section{Sexualidade e seus desdobramentos}

O conceito de sexualidade entre os/as professores/as esteve dividido em duas categorias: sexo e opção sexual ${ }^{5}$. A primeira categoria refere-se à diferenciação sexual em seus aspectos físicos (macho/fêmea) e psíquicos (masculino/ feminino), à relação sexual e afetiva entre os seres, sendo inerente à natureza humana, tendo um caráter essencialista. Nela, há supremacia dos atributos biológicos em relação aos socioculturais, embora reconhecessem que não se poderia pensá-la exclusivamente através destes.

[...] sexualidade seria as ações específicas de cada indivíduo, homem sobre a mulher, para diferenciar o homem da mulher e as coisas específicas e mais íntimas em relação aos seus órgãos, às suas vontades, aos seus anseios $[\ldots]$ (Pincel).

\footnotetext{
${ }^{5}$ Manteve-se o termo opção sexual na perspectiva de não amordaçar os/as sujeitos/as da pesquisa; entretanto, considera-se o seu uso inadequado, pois ele pressupõe a escolha de alternativas de acordo com a vontade deliberada e livre, assim, em se tratando de sexualidades, nem sempre as pessoas têm essa capacidade de escolha, dando-se preferência ao termo orientação sexual, que se relaciona ao direcionamento dos afetos das pessoas.
} 
[...] está dentro do nosso cotidiano [...] é algo natural, porém, tratada ainda, infelizmente, como algo que esteja fora de nós [...] é inerente a todo ser vivo $[. .$.$] da natureza humana [. .$.$] está para o ser humano como qualquer$ outra necessidade $[. .$.$] vida sexual [\ldots]$ (Caderno).

[...] é o beijo, contatos mais íntimos [...] O contato sexual [...] um contato sexual, relação sexual, aí seria a sexualidade em si (Borracha).

Indicaram que o tema sexualidade era muito importante e necessário para os/as estudantes, pois nele se concentravam as maiores dúvidas, e que deveria ser um assunto abordado em sala de aula. Na sexualidade, além de seus aspectos corporais, havia na percepção dos/as professores elementos espirituais e de expressão do amor entre os seres, embora estes aspectos fossem secundários aos atributos genitais e do intercurso sexual, circundados pelo caráter natural.

Contrariamente, Brandão e Heilborn (2006) inferem que a sexualidade é um conceito oriundo das ciências sociais, em que é expresso um conjunto de regras socioculturais que modelam a experiência sexual das pessoas no ocidente moderno. Sugerem, ainda, sua articulação com o gênero, que é entendido como um sistema classificatório social, no qual organiza contrastivamente os atributos masculinos e femininos em uma dada sociedade. Para Foucault (2009a), é um dispositivo histórico através do qual age uma rede de superfície em que a estimulação dos corpos, a intensificação dos prazeres, a incitação ao discurso, a formação dos conhecimentos, o reforço dos controles e das resistências estão imbricados segundo estratégias de saber e poder. Implica ou envolve mais do que corpos, resulta em fantasias, valores, linguagens, rituais, comportamentos, representações mobilizadas ou colocadas em ação para expressar desejos e prazeres (LOURO, 2007a).

Embora essa articulação entre sexualidade e gênero não tenha sido relatada de modo explícito, constata-se que ela se fez presente de forma velada, pois, conforme indica Louro (2007a), a dinâmica de poder entre os dois constructos é sutil, insinuante, exercida com discrição, quase imperceptível. Dentro desse contexto, a associação das categorias citadas, nesta pesquisa, apresenta-se sob duas perspectivas: a primeira, tendo como modelo padrão de comparação a figura do sexo masculino, pois é o homem que tem atributos sobre a mulher, indicando que é a partir dele que se constatam as diferenças percebidas no sexo oposto, marcando, dessa forma, a posição de subalternidade feminina e, a segunda, quando se utiliza o argumento das performances de gênero de cada indivíduo que marcam os estereótipos masculinos e femininos e suas diferenças biológicas, as quais são produzidas, segundo seus discursos, de forma natural, 
como um atributo inerente ao desenvolvimento humano, sem considerar a construção social desses marcadores.

É possível que esse conceito tenha suas bases no conteúdo produzido pelas ciências biológicas, que permitem a ampliação das diferenças entre os sexos como um fato natural que, por sua vez, separa os indivíduos em uma categoria binária e dicotômica, quando de fato é parte dos arranjos sociais vigentes em diferentes épocas (CITELI, 2001). Associado ao conhecimento produzido, a ciência vai ampliando cada vez mais o seu papel fundamental na construção de argumentos para o debate ideológico rumo à preservação da sexualidade como algo natural e, portanto, passível de transformação, refinamento e controle. Essa definição, a partir da oposição natureza/cultura, oriunda do Iluminismo, tem sido fundamental para embasar os modelos de relações de gênero (ROHDEN, 2003). Nessa perspectiva, a construção social de todas as formas de conhecimento, entre elas, de forma especial, o método científico, e todas as fronteiras internas e externas do conhecimento são teorizadas como movimentos de poder e não movimentos em direção à verdade (HARAWAY, 1995).

Outra perspectiva apontada por Fry (1982) é que a sexualidade tem vários sentidos e interpretações; dessa forma, considerando que antes de ser uma condição da natureza humana, é uma construção social com caráter histórico e observando as consequências geradas pelas tensões entre o que o sexo é e aquilo em que ele se transforma, é possível pensar na sua naturalidade como uma de suas representações sociais. Entretanto, é apontada como o veículo mais eficiente para a transmissão de mensagens sobre os princípios que norteiam a sociedade, agindo como transmissor de ideias, noções sociais e políticas.

Compreender a sexualidade como atributo natural, concepção compartilhada por aqueles/as que concebem a educação sexual escolar, segundo Meyer, Klein e Andrade (2007), pode excluir do processo pedagógico o caráter de construção das identidades sociais, da multiplicidade, da provisoriedade e da contingência humana, assim como os aspectos históricos, sociais, culturais e políticos que estão envolvidos na produção discursiva em educação. Os discursos, por seu turno, estão imbricados na organização das relações sociais de gênero e sexualidade e a produção de subjetividades. Ademais, aceitar a prerrogativa natural da sexualidade significa ser favorável à naturalização do feminino e, consequentemente, do masculino, desconsiderando a perspectiva de gênero, operando com uma noção do determinismo biológico (LOURO, 2007a).

Em pesquisa realizada no interior do Estado de São Paulo, professores/ as do Ensino Fundamental compreenderam a sexualidade como uma forma de descoberta, desejo, autoconhecimento, atração por pessoa do sexo oposto, sendo a expressão da naturalidade (MOIZÉS; BUENO, 2010). Percebeu-se nos achados do referido estudo que a concepção relativa à sexualidade entre 
os/as sujeitos/as estudados/as expressava uma posição de base essencialista e heteronormativa. Para Rohden (2009), não se pode negar a importância de aspectos morfofisiológicos na constituição material da sexualidade, entretanto, as predisposições biológicas não podem produzir por si só os comportamentos sexuais, a identidade de gênero ou a orientação sexual, pois elas formam um conjunto de potencialidades que apenas ganham sentido através da socialização e do aprendizado de regras culturais.

Não há nada de natural na construção do homem e da mulher, pois é um processo que acontece no âmbito cultural ao longo de toda a vida, contínua, indefinidamente, através de várias aprendizagens e práticas, empreendido de modo explícito ou dissimulado por um conjunto de instâncias sociais e culturais como: família, escola, igreja, instituições legais e médicas. É no interior de uma cultura específica que características materiais adquirem significados, produzindo diferença naturalizada através de processos discursivos e ensinada pela mídia, igreja, ciência e leis (LOURO, 2008).

A segunda categoria é relativa à orientação sexual, pensada através da homossexualidade e da heterossexualidade. Nela observou-se o uso do termo opção sexual com a conotação de escolha da identidade de gênero/sexual, sendo que esta pode ser influenciada por outras pessoas quando não se tem ainda uma posição definida e a adolescência apresenta os elementos fundamentais do processo transitório, no qual essa influência pode agir de maneira mais efetiva. Nesse aspecto, as tensões produzidas em torno do debate em uma sociedade, hegemonicamente, branca, masculina, heterossexual e cristã, quanto ao respeito à diversidade sexual, foram introduzidas logo no início do discurso ao se afirmar o caráter polêmico do tema.

[...] é um tema bem polêmico devido à questão atual, da questão da homossexualidade, da questão da heterossexualidade, porque os alunos eles ainda estão começando a adolescência, às vezes não têm ainda uma opção sexual definida [...] (Lápis).

Esse caráter polêmico pode estar vinculado à discussão atual sobre a criminalização da homofobia. Uma forma de discriminação menos discutida e a mais consentida na presença de outras pessoas que não são as vítimas consiste em designar o/a outro/a como inferior, contrário ou anormal, de modo que sua diferença o/a coloca em situação de abjeto; pode ser também entendida como uma aversão social e coletiva a tudo aquilo que aparente ser homossexual, traduzida em forma preconceituosa de tratamento dispensada aos homossexuais. Reflete, 
portanto, a sociedade de forma mais ampla e seus grupos sociais, que, em geral, foram construídos sobre a ideia do preconceito à diferença, entendendo a heterossexualidade como normal e natural (BORGES et al., 2011). Contudo, é válido ressaltar que homossexualidade e heterossexualidade são construções discursivas da modernidade e, nesse sentido, não há uma condição, comportamento ou orientação sexual que possa ser definido como natural (SOUZA; DINIS, 2010).

Evidenciou-se, no argumento apresentado por Lápis, a possibilidade de influência de um/a homossexual sobre a orientação sexual de um/a jovem. Esse suposto perigo seria diretamente proporcional à idade, ou seja, quanto mais jovem, mais indefesa, mais influenciável. Entretanto, essa ideia pauta-se no mito de que as identidades sexuais, a partir da adolescência, já estariam solidamente estruturadas, enquanto na infância existiria um espaço fértil para incutir sugestões quanto à orientação sexual (SOUZA; DINIS, 2010).

$\mathrm{Na}$ opinião de Britzman (2009), dentro do espaço escolar, as abordagens educacionais sobre a homossexualidade são apáticas, tendem a considerá-la uma anomalia, o amor homossexual não é discutido, está centrada na descoberta de estereótipos e, dessa forma, a ordem hierárquica é mantida por meio de um discurso de tolerância que reforça a intolerância. O desejo é fragmentado, o debate centra-se em torno das causas da orientação sexual em um duelo opositor entre natureza e cultura, sem considerar que a diversidade humana das preferências sexuais, estilos de amar e modos de ser são um fato da vida.

Além da consideração de que a diversidade sexual faz parte da experiência humana, é importante salientar que a constituição do/a sujeito/a homossexual/ heterossexual é também histórica. Foi a partir de 1870 que os psiquiatras começaram a utilizar a homossexualidade como objeto de análise médica. Desse modo, o termo heterossexualidade teria sido criado por volta de 1892 e designava, na ocasião, o amor patológico e desmedido por pessoa do sexo oposto; somente ulteriormente adquiriu o sentido de norma e de referência para a orientação sexual (DINIS; CAVALCANTI, 2008; FOUCAULT, 2009b).

Um aspecto congruente em ambas as categorias de análise é a oposição binária entre os gêneros e a afetividade: homem/mulher e homossexual/heterossexual. Louro (2007b) indica que são constantes a polaridade e a dicotomia nas análises e compreensões das sociedades, uma vez que homens e mulheres, usualmente, são concebidos como polos opostos que se relacionam dentro de uma lógica de dominação-subordinação, entretanto, essa forma de pensar não reconhece ou representa muitas pessoas que vivem suas feminilidades e masculinidades de diferentes formas das hegemônicas. Contudo, o grande desafio talvez seja admitir que as fronteiras sexuais e de gênero são constantemente atravessadas e que o lugar social no qual alguns/mas sujeitos/as vivem é a fronteira, a posição de ambiguidade entre as identidades de gênero/sexuais (LOURO, 2008). 


\section{Pressupostos teóricos da educação sexual}

Acerca do tema educação sexual, os/as professores/as indicaram que o processo ensino-aprendizagem deveria estar pautado sobre três eixos principais, os quais norteariam o entendimento conceitual docente do assunto. O primeiro eixo seria a relação sexual, em que por meio dela os/as adolescentes seriam preparados/as para o ato sexual com responsabilidade, evitando a gravidez na adolescência e as infecções sexualmente transmissíveis.

Seria uma preparação dos adolescentes [...] para conviver de uma maneira saudável $[. .$.$] com o contato sexual, mas através da responsabilidade$ [...] pode levar a uma gravidez, pode levar a uma doença sexualmente transmissível, então quando tem uma educação sexual, ele tem a informação, então se tem a informação, o adolescente ou a pessoa que vai manter o contato sexual, ela vai ter maior responsabilidade [...] (Borracha).

[...] exige por parte de todos nós educadores um pouco mais de bom senso, de coerência [...] o ato sexual, a convivência sexual na sociedade por muito tempo foi tratada com muito tabu [...] a sociedade até alcançou essa liberdade, mas não alcançou em muitas partes as responsabilidades que deveria ter (Caderno).

A educação sexual, no Brasil, foi incluída no currículo escolar a partir da década de 1960. Em 1971, as Diretrizes e Bases da Educação Brasileira começaram a promover programas de saúde escolares, nos quais a sexualidade era discutida, essencialmente, para prevenir a gravidez na adolescência e as Doenças Sexualmente Transmissíveis (DST). Após 1992, o foco de atenção voltou-se para a prevenção do HIV/aids. No fim dos anos 1990, uma abordagem mais positiva foi implantada através dos $\mathrm{PCN}$, embora estes ainda recebam críticas devido ao insuficiente conhecimento acerca das questões culturais e históricas que permeiam a sexualidade, pois ainda permanece definida como um aspecto biológico e essencializado da vida humana, o que a impede de ser discutida de forma não discriminatória e sensível cultural e historicamente (MOSCHETA; MACNAMEE; SANTOS, 2011).

Os PCN indicam que o processo pedagógico de educação sexual deve ser formal e sistematizado no espaço escolar e que a intervenção deve ser realizada pelos/as educadores/as de forma planejada, abordando diversos pontos de vista, valores e crenças existentes na sociedade para ajudar o/a estudante a encontrar 
um ponto de autorreferência por meio da reflexão, porém, as temáticas devem ser abordadas no limite da ação pedagógica, sem invadir a intimidade e o comportamento de cada pessoa (BRASIL, 2000).

Observou-se, ainda, nos depoimentos, que na percepção docente a educação sexual, vinculada aos aspectos informativos e associada ao bom senso, é a chave principal para estimular nos/as adolescentes comportamentos sexuais classificados como saudáveis e responsáveis. É sinalizada, ainda, a mudança de paradigma quanto ao tratamento que a sociedade atribui à sexualidade, o qual, nos dias atuais, perde seu status de tabu, uma vez que as vivências e práticas sexuais têm conquistado maior liberdade de expressão. Essa liberdade pode estar relacionada à maior abertura de diálogo sobre sexo, exposição midiática de temas relacionados à sexualidade, desvinculação do prazer e maternidade, aumento das expressões sexuais e erotização precoce.

Ademais, em outros momentos, verificou-se que os/as professores/as acreditavam que a educação sexual era uma matéria relevante que deveria ser trabalhada desde o quarto ou quinto ano do Ensino Fundamental, pois para os/ as jovens, embora detivessem um saber prático sobre o assunto, faltava-lhes o conhecimento teórico, aliado à mídia que prejudicava o processo educativo, mostrando o sexo explícito, o que dificultava a prevenção das relações sexuais.

Surgiu nesse momento o aspecto proscritivo do ato sexual sob duas perspectivas. A primeira é que há um espaço legitimado para se falar de sexo, que nesse caso é a escola. A segunda é que o processo educativo deve objetivar a abstinência sexual e, consequentemente, adiar a sexarca. Discorrendo sobre esse tema, Foucault (2009b) afirma que na sociedade pode-se falar de sexualidade apenas para proibi-la, que o seu esclarecimento foi realizado no âmbito dos discursos, das instituições e das práticas e que as proibições são enfatizadas, fortes e numerosas, mas que fazem parte de um sistema complexo em que coabitam ao lado das incitações, das manifestações e das valorizações.

O segundo eixo, a fisiologia corporal, refere-se às transformações corporais que diferenciam o sexo em seu aspecto biológico (ovulação, menstruação, fecundação) e suas influências hormonais. Relatam que todo/a professor/a deve estar preparado/a para abordar essas questões em sala de aula, para que o/a estudante possa conhecer o corpo e os processos corporais que acompanham o desenvolvimento humano, especialmente na adolescência.

[...] deve ser começada na escola desde o quinto ano onde a criança vai aprender a questão de homem e de mulher, desde a questão da menstruação, a questão da ovulação, a questão do homem se transformando, o menino se transformando em homem [...] todo o processo de fecundação [...] nas aulas de ciências [...] (Lápis). 
[...] todo professor tem que estar preparado para abordar esse tema em sala de aula $[\ldots]$ surge mais por questão hormonal e tudo, na adolescência ela aparece constante (Livro).

Nesse aspecto do processo educativo, constatou-se que o corpo em sua matriz biológica era o tema central. Assim, dentro dessa perspectiva, pôde-se inferir que os comportamentos adolescentes eram modulados por um feedback hormonal. Nesse sentido, os/as docentes afirmaram que as aulas de ciências eram o espaço mais oportuno para se implementar a educação sexual, uma vez que a Biologia foi considerada a área do conhecimento que ganhou legitimidade e autoridade para discutir tais assuntos, a partir da relação direta com a ênfase do discurso científico. Entretanto, a estratégia do saber cientificamente qualificado, centrado nas ciências naturais, foi determinante para se estabelecer relações de poder, nas quais se tentam produzir verdades absolutas.

Destaca-se, nesse sentido, que o pressuposto teórico que baseia essa abordagem é uma visão biologizante da sexualidade. Dessa forma, é muito frequente o predomínio das questões relativas à sexualidade serem apresentadas no espaço escolar, quase que exclusivamente, pelas disciplinas biomédicas (BORGES et al., 2011). Esse limite da dimensão biológica da educação sexual parece estar relacionado à ineficaz formação acadêmica e continuada dos/as professores/as, que não aborda questões históricas, culturais, sociais e relacionais da sexualidade, uma vez que estes/as reconhecem a necessidade de capacitação para melhor desempenharem sua ação pedagógica, pois não se consideram preparados/as ou seguros/as para desenvolver uma orientação mais efetiva.

Para Foucault (2009a), do ponto de vista histórico, há dois procedimentos para produzir a verdade do sexo: ars erotica e scientia sexualis. Na primeira, ela é produzida pela experiência, encarada como prática e extraída do prazer, que deve ser conhecido como tal, segundo sua intensidade, qualidade específica, duração e manifestações no corpo e na alma; constitui-se um saber secreto para não perder sua eficácia e deve ser transmitido de modo esotérico através de uma iniciação de um/a discípulo/a pelo/a mestre/a. A segunda, característica da sociedade desenvolveu mecanismos ordenados, quanto ao essencial, em função da confissão, a qual difundiu seus efeitos na medicina, na justiça, na pedagogia, nas relações interpessoais, familiares e amorosas. Este parece ser o subsídio fundamental para o desenvolvimento de uma ciência sexual.

Pensar o êxito da educação sexual no ambiente escolar é centrar o/a professor/a como personagem principal desse processo, pois atitudes e conhecimentos são transmitidos diretamente para os/as estudantes e podem ser 
alterados pela formação complementar e pelo envolvimento em experiências de ensino-aprendizagem para a sexualidade (RAMIRO; MATOS, 2008). Nesse sentido, a instituição escolar, assim como outras estruturas sociais, pela ação de seus/suas atores e atrizes, desempenha papel especial na produção de identidades sexuais e de gênero, assim como na validação de determinadas formas de viver as masculinidades, as feminilidades e as sexualidades (MEYER; KLEIN; ANDRADE, 2007).

No terceiro eixo, são apontados aspectos do comportamento social que envolvem as ações praticadas por homens e mulheres no contexto social do desempenho de seus papéis e o comportamento sexual nas relações, o que foi denominado de opção sexual, destacando que cada pessoa tem seu papel e responsabilidade na orientação dos/as adolescentes, sendo um trabalho compartilhado. Salienta-se, também, o preconceito quanto à diversidade sexual, que é um aspecto atual da sociedade.

[...] conhecer também as ações sociais, a questão do comportamento da relação [...] e o sexo opção [...] entender por que acontece, como deve ser tratado [...] a questão de comportamento sexual, de opção sexual [...] orientar, trazer essas orientações para eles, para tirar algumas dúvidas [...] para tentar entender, para tentar explicar alguma coisa, para que o aluno tenha um norte [...] do que ele quer, do que é melhor para ele, e do que se identifica mais com ele $[\ldots]$ (Pincel).

Pôde-se inferir que nesse eixo deveriam ser incluídas, na educação sexual, as relações de gênero que permeiam as relações interpessoais dos/as sujeitos/as. É importante notar que entre os/as docentes pesquisados/as apenas Pincel destacou a necessidade de se dialogar essas questões. Problematizar as construções sociais do masculino e do feminino, em uma proposta pedagógica, é uma forma de construir uma equidade de gênero, pois as diferenças biológicas servem de argumento para justificar uma série de desigualdades sociais entre homens e mulheres, que, por sua vez, formam a base para justificar comportamentos de mulheres e homens (ALTMANN; MARTINS, 2009).

Assim, trabalhar com os pressupostos das relações de gênero é aceitar que não há uma compreensão única do seu conceito e significa, também, posicionar-se contrariamente à naturalização do masculino e do feminino (LOURO, 2007a). Entretanto, incorporar essa perspectiva não é uma tarefa fácil, pois a simples substituição dos parâmetros essencialistas por uma prática centrada na desconstrução das concepções existentes não eliminaria todas as relações de poder e 
discriminações reproduzidas no espaço escolar; todavia, é fundamental que os aspectos heteronormativos sejam questionados e, talvez, seja esse o ponto de partida para o entendimento da formação das identidades sexuais e de gênero (SOUZA; DINIS, 2010).

A despeito dos aspectos de gênero estarem secundários aos biológicos, constatou-se que os/as professores/as estavam alinhados aos Parâmetros Curriculares Nacionais quanto aos conteúdos de educação sexual que deveriam ser trabalhados em sala de aula. Segundo os PCN, os conteúdos devem ser organizados em três blocos: Corpo - matriz da sexualidade; Relações de gênero; Prevenção às doenças sexualmente transmissíveis/aids. O primeiro refere-se à infraestrutura biológica e o aparato herdado e constitucional dos seres humanos, sendo o corpo entendido como o resultado da aprendizagem através de suas vivências na interação com o meio. Nas relações de gênero, deve ser incluída a discussão das relações autoritárias, a rigidez dos padrões de conduta estabelecidos para homens e mulheres e suas transformações. Por último, devem ser fornecidas informações sobre as doenças com foco na promoção de condutas preventivas e ênfase na distinção entre as formas de contágio (BRASIL, 2000).

Concorda-se que abordar a sexualidade em suas múltiplas dimensões é um desafio para o/a professor/a que necessita implementar práticas pedagógicas alinhadas às práticas conceituais, pois esse trabalho exige a integração de disciplinas, conhecimentos específicos e qualificações humanas, como habilidades, competências, atitudes e valores (LIMA; VASCONCELOS, 2006). Assim, como a formação docente, em geral, encontra-se fragilizada quanto às questões sociais, culturais e históricas da sexualidade e sua articulação com as relações de gênero, para que se alcance a apropriação teórica necessária é preciso que os/ as docentes tenham acesso a um espaço coletivo de produção de conhecimento plural, reconheçam os valores que norteiam suas condutas, estejam sensibilizados quanto à existência da diversidade sexual e reflitam sobre os princípios democráticos que devem ser alcançados (ALMEIDA et al., 2010).

\section{Considerações finais}

O trabalho de natureza conceitual desenvolvido neste estudo permitiu que a percepção dos/as professores/as do Ensino Fundamental e Médio de uma escola pública sobre a sexualidade e educação sexual fosse acessada e, dessa forma, as potencialidades e as fragilidades da sua práxis pedagógica pudessem ser identificadas, as quais poderão subsidiar investimentos didáticos para a con- 
secução de uma experiência docente mais efetiva quanto aos assuntos relativos à sexualidade e seus desdobramentos teóricos, sociais, culturais, históricos e relacionais.

A sexualidade é pensada através dos seus aspectos biológicos e do direcionamento dos afetos no seu exercício. Apresenta-se com um caráter essencialista e as relações com as concepções de gênero são expostas de forma subliminar. De forma secundária, há na sua constituição elementos psíquicos, afetivos e espirituais; no entanto, os aspectos históricos e socioculturais são desconsiderados. Esse conceito pode estar relacionado às vivências pessoais e à formação acadêmica e continuada dos/as professores/as, que, por sua vez, pauta-se, substancialmente, no modelo científico legitimado pela sociedade atual, pois ainda são as ciências biológicas socialmente referendadas para se falar de sexualidade e sexo, o que, nessa perspectiva, amplia a naturalização desse constructo social.

Os/as professore/as entendem que a educação sexual é um processo de orientação, no qual ocorreria a preparação dos/as adolescentes para a relação sexual, prevenção das infecções sexualmente transmissíveis e gravidez, descrição da fisiologia e desenvolvimento corporal e conhecimento das relações sociais que modulam os papéis de gênero e da orientação sexual. Deve ser iniciada no quarto ou quinto ano do Ensino Fundamental, cujas aulas de ciências são o espaço privilegiado para se realizar tal orientação. A informação é a forma mais eficaz para se assumir comportamentos responsáveis e saudáveis, sendo que deve ser embasada pela coerência e bom senso dos/as educadores/as.

A mídia foi apontada como prejudicial para o processo de educação sexual no espaço escolar por mostrar o sexo explícito, promovendo erotização corporal e, assim, impedir a prevenção das relações sexuais. Nesse momento, constata-se o aspecto proibitivo da sexualidade/sexo e para alguns/mas professores/as o objetivo da intervenção pedagógica estaria localizado na regulação da atividade sexual dos/as jovens em uma apologia à abstinência sexual. Paradoxalmente, como as respostas corporais são moduladas pela descarga hormonal, própria da adolescência, esse controle seria de difícil alcance e os comportamentos decorrentes dessa influência não teriam correlação com o meio sociocultural, recaindo sobre um determinismo biológico.

Destaca-se que apenas um/a professor/a fez referência aos papéis sociais de gênero na abordagem da educação sexual dos/as adolescentes, o que, na nossa avaliação, não é diferente do que é preconizado pelos $\mathrm{PCN}$, uma vez que há nos blocos de conteúdos predomínio de assuntos relacionados aos aspectos biomédicos. Entretanto, merece atenção o fato de as relações de gênero não serem articuladas aos aspectos corporais, preventivos e patológicos. Essa articulação é fundamental para o entendimento de como se operam os proces- 
sos socioculturais que determinam a construção de categorias como: mulher, homem, corpo, identidade sexual, performances sexuais e orientação sexual, por exemplo. Assim como é primordial para perceber que os comportamentos preventivos em relação ao uso de preservativos e gravidez são norteados por essas relações, pois os princípios de condutas incidentes sobre a sexualidade de homens e mulheres são distintos.

Observa-se uma limitação conceitual ao usar o termo opção sexual como sinônimo de orientação sexual, tanto ao se falar em sexualidade quanto em educação sexual, e isso denota a pouca atualização sobre o assunto. Prefere-se, nesse sentido, usar o constructo orientação sexual, por ser mais adequado. Os comportamentos sexuais e as performances de gênero começam a se delinear na infância, através das experiências infantis e da identificação com os gêneros, ocasião na qual a criança não possui uma capacidade avaliativa de realizar uma escolha e, portanto, fazer sua opção sexual. Essas experiências caracterizam-se por sua fluidez e transitoriedade, por conseguinte, não são fixas e predeterminadas. Soma-se a esse aspecto a consideração de que o uso do termo opção indicaria a escolha de uma forma de desejo e, nessa perspectiva, nem o/a heterossexual e nem o/a homossexual fizeram essa escolha.

Como potencialidades, aponta-se: o reconhecimento, por parte dos/as professores/as, de suas limitações conceituais e a disponibilidade para a capacitação, o que demonstra a sensibilidade para problematizar a discussão sobre sexualidade no espaço escolar, concordando que o tema tem relevância social para ser implementado; a honestidade dos/as docentes ao perceberem suas fragilidades pedagógicas, admitindo que necessitam se atualizar, incorporando outros elementos de análise para atender à demanda atual dos/as educandos/as; o entendimento de que a implementação de um processo didático-pedagógico sobre a educação sexual requer a participação compartilhada de outras instâncias sociais, como a família, dividindo com elas as responsabilidades; e a transversalidade, ao afirmarem que todo/a professor/a precisa estar preparado/a para realizar um investimento educativo sobre o assunto, atendendo às solicitações $\mathrm{e}$ às necessidades dos/as adolescentes.

Reconhece-se que os investimentos na formação continuada dos/as educadores/as têm sido um aspecto ainda fragilizado e que pode influenciar sobremaneira o preparo técnico e emocional dos/as professores/as na efetivação e no aprofundamento da educação sexual no âmbito escolar. Assim, os resultados encontrados nesta pesquisa indicam que o trabalho docente necessita de constante renovação, é preciso superar o modelo biomédico/científico na sexualidade, considerando suas dimensões histórica, social e cultural, e que a transversalidade das ações é uma meta que deve ser alcançada nos diversos campos do saber. 


\section{REFERÊNCIAS}

ALMEIDA, Sandra Aparecida de; NOGUEIRA, Jordana de Almeida; LACERDA, Sheylla Nadjane Batista; TORRES, Gilson Vasconcelos. Orientação sexual no contexto escolar: discurso oficial versus cotidiano pedagógico. Revista de Enfermagem da UFPE, v. 4, n. especial, p. 1906-1912, nov./dez. 2010.

ALTMANN, Helena; MARTINS, Carlos José. Educação sexual: ética, liberdade e autonomia. Educar em Revista, n. 35, p. 63-80, 2009.

ARENAS, Reinaldo. Antes que anoiteça. Tradução de: Irène Cubric. Rio de Janeiro: BestBolso, 2009.

BORGES, Zulmira Newlands; PASSAMANI, Guilherme Rodrigues; OHLWEILER, Mariane Inês; BULSING, Muriel. Percepção de professoras de ensino médio e fundamental sobre a homofobia na escola em Santa Maria (Rio Grande do Sul/Brasil). Educar em Revista, n. 39, p. 21-38, jan./abr. 2011.

BRANDÃO, Elaine Reis; HEILBORN, Maria Luiza. Sexualidade e gravidez na adolescência entre jovens de camadas médias do Rio de Janeiro, Brasil. Cadernos de Saúde Pública, v. 22, n. 7, p. 1421-1430, jul. 2006.

BRASIL. Secretaria de Educação Fundamental. Parâmetros Curriculares Nacionais: apresentação dos temas transversais: ética. 2. ed. Rio de Janeiro: DP\&A, 2000.

BRITZMAN, Deborah P. Professor@s e eros. Educarem Revista, n. 35, p. 53-62, 2009. CITELI, Maria Teresa. Fazendo diferenças: teorias sobre gênero, corpo e comportamento. Estudos Feministas, v. 1, ano 9, p. 131-145, 2001.

COSTA, Lucia Helena Rodrigues; COELHO, Edméia Coelho de Almeida. Nursing and sexuality: Integrative review of papers published by the Latin-American Journal of Nursing and Brazilian Journal of Nursing. Revista Latino-Americana de Enfermagem, v. 19, n. 3, p. 631-639, mai./jun. 2011.

DINIS, Nilson Fernandes; CAVALCANTI, Roberta Ferreira. Discursos sobre homossexualidade e gênero na formação em pedagogia. Pro-Posições, v. 19, n. 2, p. 99-109, maio/ago. 2008.

FOUCAULT, Michel. História da sexualidade I: A vontade de saber. 19. ed. Tradução de: Maria Thereza da Costa Albuquerque e J. A. Guilhon Albuquerque Rio de Janeiro: Edições Graal, 2009a. . Microfísica do poder. Rio de Janeiro: Graal, 2009b.

FRY, Peter. Para inglês ver: identidade e política na cultura brasileira. Rio de Janeiro: Zahar Editores, 1982.

GIL, Antônio Carlos. Métodos e técnicas de pesquisa social. 6. ed. São Paulo: Atlas, 2009. HARAWAY, Donna. Saberes localizados: a questão da ciência para o feminismo e o privilégio da perspectiva parcial. Cadernos Pagu, v. 5, p. 7-41, 1995. 
IBGE. Instituto Brasileiro de Geografia e Estatística. Estimativa Populacional dos Municípios do Ceará em 2009. Disponível em: <http://dialogospoliticos.wordpress. com/2009/08/15/ibge-estimativa-populacional-dos-municipios-do-ceara-em-2009/>. Acesso em: 5/6/2010.

JARDIM, Dulcilene Pereira; BRÊTAS, José Roberto da Silva. Orientação sexual na escola: a concepção dos professores de Jandira - SP. Revista Brasileira de Enfermagem, v. 56, n. 2, p. 157-162, mar./abr. 2006.

LIMA, Kênio Erithon Cavalcante; VASCONCELOS, Simão Dias. Análise da metodologia de ensino de ciências nas escolas da rede municipal de Recife. Ensaio: avaliação de políticas públicas em educação, v. 14, n. 52, p. 397-412, jul./set. 2006.

LOURO, Guacira Lopes. Gênero, sexualidade e educação: das afinidades políticas às tensões teórico-metodológicas. Educação em Revista, n. 46, p. 201-218, dez. 2007a.

. Gênero, sexualidade e educação: uma perspectiva pós-estruturalista. 9. ed. Petrópolis, RJ: Editora Vozes, $2007 \mathrm{~b}$.

. Gênero e sexualidade: pedagogias contemporâneas. Pro-Posições, v. 19, n. 2 , p. 17-23, mai./ago. 2008.

MEYER, Dagmar Elisabeth Estermann; KLEIN, Carin; ANDRADE, Sandra dos Santos. Sexualidade, prazeres e vulnerabilidade: implicações educativas. Educação em Revista, n. 46, p. 219-239, dez. 2007.

MINAYO, Maria Cecília de Souza. O desafio do conhecimento: pesquisa qualitativa em saúde. 11. ed. São Paulo: Editora Hucitec, 2008.

MOIZÉS, Julieta Seixas; BUENO, Sonia Maria Villela. Compreensão sobre sexualidade e sexo nas escolas segundo professores do ensino fundamental. Revista da Escola de Enfermagem da USP, v. 44, n. 1, p. 205-212, 2010.

MOSCHETA, Murilo dos Santos; MACNAMEE, Sheila; SANTOS, Jucely Cardoso dos. Dialogue and transformation: embracing sexual diversity in the educational context. Educar em Revista, n. 39, p. 103-122, jan./abr. 2011.

RAMIRO, Lúcia; MATOS, Margarida Gaspar de. Percepções de professores portugueses sobre educação sexual. Revista de Saúde Pública, v. 42, n. 4, p. 684-692, 2008.

ROHDEN, Fabíola. A construção da diferença sexual na medicina. Cadernos de Saúde Pública, v. 19, supl. 2, p. S201-S212, 2003.

. Gênero, sexualidade e raça/etnia: desafios transversais na formação do professor. Cadernos de Pesquisa, v. 39, n. 136, p. 157-174, jan./abr. 2009.

SOUZA, Leandro Corsico; DINIS, Nilson Fernandes. Discursos sobre homossexualidade e gênero na formação docente em biologia. Pro-Posições, v. 21, n. 3, p. 119-134, set./dez. 2010.

Texto recebido em 18 de janeiro de 2012 .

Texto aprovado em 01 de março de 2012. 